\title{
Complete Homeopathic Cure of Leukemic Patient Suffering
}

\section{Diarrhea}

\section{Seyedaghanoor $\mathrm{S}^{*}$}

Homeopathic Physician, Tehran, Iran

*Corresponding author: Seyedaghanoor Sadeghi, Homeopathic Physician, No.1. Delbaz Alley Baradarane Teimoorifarst, Masile Jajrud Ave. Damavand Ave. Tehran, Iran, Tel: +989120379815; E-mail: drsadeghi.h@gmail.com

\section{Mini Review \\ Volume 2 Issue 1}

Received Date: November 20, 2017

Published Date: January 02, 2018

DOI: $10.23880 /$ mjccs-16000126

\section{Abstract}

Hospital infectious diarrhea is very common especially in patients suffering Acute Myeloid leukemia. Preventive measures should be considered in such patients especially in elder people to prevent infections. Washing hands is the most important and maybe the easiest preventive act to be done by hospital personnel especially in intensive care units. A rather tall old man aged 84, was admitted at a general hospital in Tehran because of suffering from severe low back pain due to metastatic lesions, at the oncology ward about 4months ago. For the first time, about 8 months ago, he felt severe pain in his back and was examined by a physician, in the March 2017. Radiologic images showed lumbar vertebrate fracture due to leukemic metastatic lesion, since then he was treated by conventional drugs. After being admitted in the hospital to palliate his severe back pain, he was afflicted by an acute diarrhea for 15 days. His daughter called up the author and asked for homeopathic healing of his crippling diarrhea, not treated by conventional medicines after 15 days. The next day she came to the clinic and homeopathic Arsenicum album 6x was prescribed regarding his father's constitution. She gave his father a single dose of 4 drops of the remedy. The next day diarrhea stopped. Thus he was discharged from the hospital and was taken to his home. The patient felt better but could not yet sit or stand and walk on his own. She was said to give her father 1 drop of the remedy after shaking 8 times, 3 times a day. He gradually felt better and more energetic, so that he asked his wife to help him go out for walking and sitting in the park near their home. His appetite improved and started eating food and drinking water. Thus randomized clinical trials are suggested to assess the efficacy of the remedy in similar patients and to show the efficacy of homeopathic remedy, Arsenicum album in healing diarrhea in leukemic patients.

Keywords: Leukemia; Diarrhea; Homeopathic Arsenicum Album

\section{Introduction}

Acute myeloid leukemia causes neoplastic proliferation of blast cells, derived from bone marrow myeloid elements. It is a very rapidly progressive malignancy, death in 2 months if untreated, about $20 \%$ of the patients experience a 3 year survival after chemotherapy. $1 / 10,000 / y r$. The incidence increases with age, and is the 


\section{Medical Journal of Clinical Trials \& Case Studies}

commonest acute leaukemia of the adults. Seen increasingly as a long-term complication of chemotherapy, eg for lymphoma. Also associated with myelodysplastic syndromes, including radiation and syndromes like Down's. Infection is the major problem, related to both the disease and during treatment. We should be alert to septicemia. Infections may be bacterial, fungal or viral, and prophylaxis is given for each during treatment. Infectious diarrhea occurred in this case. It was not treated at all, in spite of using various kinds of antibiotics by the hospital staff, after 15 days of prescribing different types of antibiotics. However one single dose of homeopathic Arsenicum album stopped the patient's diarrhea, a complete cure.

\section{Arsenicum Album Personality Type}

Homeopathic remedies return balance and equilibrium to the body that has imbalanced due to various factors including bacterial infections, explained in the above case. People with this type of personality, have very characteristic symptoms and signs, called rubrics in homeopathy. The main mental rubric is feeling insecure. Insecurity forces them to seek companion, to keep their money in bank and to raise it as much as possible or to keep it at home in a secure place, to lock all doors before going to bed. They are afraid of robbers, so they put a knife or rifle besides them or under their beds, to defend themselves if attacked by a robber. The author asked the patient's daughter such keynote rubrics before prescribing the remedy. Another keynote rubric is that they get affected by gastrointestinal problems especially diarrhea and or nausea and vomiting. Arsenicum album is the $1^{\text {st }}$ choice remedy in infectious diarrhea with or without nausea and vomiting.

Some other rubrics of Arsenicum album is as follows:

- Great anguish and restlessness; changes place continuously.

- Fears of death, of being alone. Great fear, with cold sweat.

- Feels it is useless to take medicine. Suicidal. Hallucinations of smell and sight.

- Headaches relieved by cold, other symptoms aggravated by cold.
- Scalp itches intolerably.

- Burning in eyes with acrid lachrymation.

- Thin nose, watery, excoriating discharge.

- Swollen face; pale, yellow, cachectic, sunken, cold and covered with sweat.

- Unhealthy, easily bleeding gums. Ulceration of mouth (aphthae) with dryness and burning heat (cancrumoris). Epithelioma of lips.

- Swollen, oedematous, constricted, burning, unable to swallow.

- Cannot bear the sight or smell of food. Great thirst; drinks much, but little at a time.

- Nausea, retching, vomiting after eating or drinking. Anxiety in the pit of stomach. Burning pain.

- Palpitations, pain, dyspnea, faintness. Irritable heart in smokers and tobacco chewers.

- Cramps in calves. Swelling of foot. Sciatica. Diabetic gangrene.

- Paralysis of the lower limbs with atrophy.

- High temperature. Septic fevers. Intermittent fevers. Hay fever.

- Leukemia is another rubric curable with Arsenicum album.

Asenicum album can treat or heal the above rubrics in the affected patients.

\section{Conclusions}

Homeopathic remedy, Arsenicum album is one of the major homeopathic remedies, used in various conditions, including gastrointestinal disorders like diarrhea. It is suggested to be used in a random clinical trial to show its efficacy to heal the above rubrics in leukemic patients.

\section{References}

1. Longmore M, Wilkinson I, Turmezei T, Cheung CK, Smith E (2007) Oxford Handbook of Clinical Medicine. $7^{\text {th }}$ (Edn.), Oxford University Press, UK.

2. William Boericke (2000) BOERICKE'S New Manual of Homeopathic Materia Medica.

3. Mathur KN (2005) Systematic Materia Medica of Homeopathic Remedies. 